\title{
Congenital Umbilical Appendix Misdiagnosed as Umbilical Granuloma: Report of 2 Cases
}

\author{
Ghoroubi J, Mohajerzadeh L, Lotfollahzadeh S, Atqiaee K*
}

Pediatric Surgery Research Center, Research Institute for Children Health, Shahid Beheshti University of Medical Sciences, Tehran, Iran

\section{ABSTRACT}

Background: Umbilical cord hernia is an uncommon umbilical anomaly which develops during 10th to 12th weeks of gestational age owing to failure of complete bowel return into coelomic cavity. In extremely rare cases appendix is the only trapped organ in hernia sac which may erode the overlying membrane and simulate umbilical granuloma.

Case Report: Two infants presented with delayed umbilical cord separation with a reddish mass at umbilicus which was initially diagnosed as umbilical granuloma. Surgical exploration on failure of conservative measures revealed it as vermiform appendix. Appendectomy was done in both cases.

Conclusion: Vermiform appendix at umbilicus is a rare congenital anomaly and may simulate other pathologies at umbilicus.

\section{Key words: Umbilical cord hernia; Umbilical Appendix; Umbilical granuloma}

Correspondence*: Khashayar Atqiaee, Pediatric Surgery Research Center, Shahid Beheshti University of Medical Sciences, and Tehran, Iran.

E-mail: khashayaratqiaee@gmail.com

Submitted: 05-06-2018

Conflict of Interest: None
(C) 2018, Ghoroubi et al

Accepted: 28-06-2018

Source of Support: Nil

This is an open-access article distributed under the terms of the Creative Commons Attribution License, which permits unrestricted use, distribution, and reproduction in any medium, provided the original work is properly cited.

\section{INTRODUCTION}

Umbilical anomalies in pediatric population are common. However umbilical cord hernias are rare and described as congenital defects in umbilicus leading to herniation of viscera. Unusual and uncommon herniations have been described in literature including liver, gallbladder, midgut with and without atresias, and vitellointestinal duct.[1,2]

isolated herniation of vermiform appendix as a content of hernia of umbilical cord is a rarity and is called as umbilical appendix. Herein, we report two cases of umbilical appendix which were initially managed as cases of umbilical granuloma.

\section{CASE REPORT}

Our patients were a one-month-old girl (case I) and a forty-five days old boy (case II) born of uneventful normal vaginal delivery. Both had normal Apgar score at birth and born to 26 and 28-year-old healthy mother, respectively. Primary neonatal physical examinations did not mention any pathological findings. Their body weights at the time of presentation were $5 \mathrm{~kg}$ and 4.5 $\mathrm{kg}$ respectively. (>95th percentile). The babies had history of delayed separation of umbilical stump, at 22 and 25 days in case I and II, respectively.

On examination, a small reddish tissue measuring up to $1 \mathrm{~cm}$ seen protruding from the umbilicus with small 
amount of discharge (Figure 1). Initially they underwent a course of medical treatment with the impression of umbilical granuloma by a neonatologist. Ultimately both were referred to Pediatric Surgery Clinic for further management.

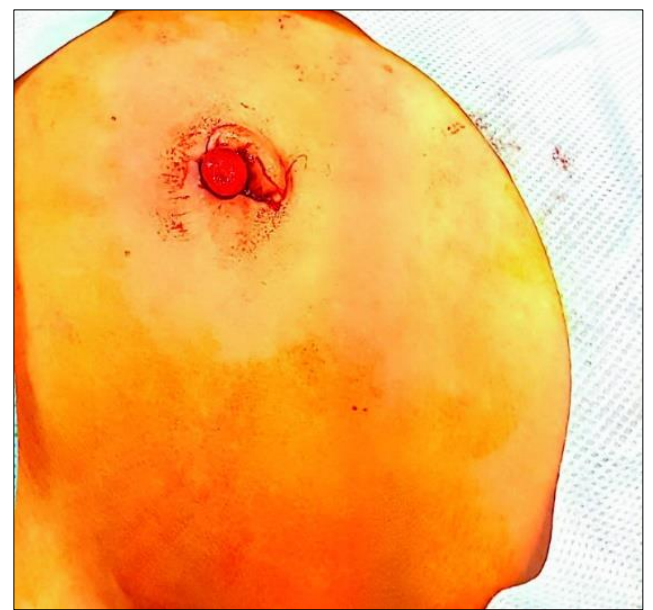

Figure 1: One month old baby with the small reddish tissue protruding from umbilicus

Since both patients have been managed medically for a long time, and due to size of protruding tissue, they were planned for umbilical exploration. Routine preoperative laboratory tests were reported as normal. The surgical operations were done under general anesthesia with semi-curvilinear incision beneath umbilicus.

A protruded tissue at umbilicus was dissected out which turned out to be the normal appendices Figure 2). Further exploration revealed no other abnormalities besides a mobile cecum. Appendectomy was done in both patients and postoperative course was uneventful. Histopathology reported normal appendicular tissue.

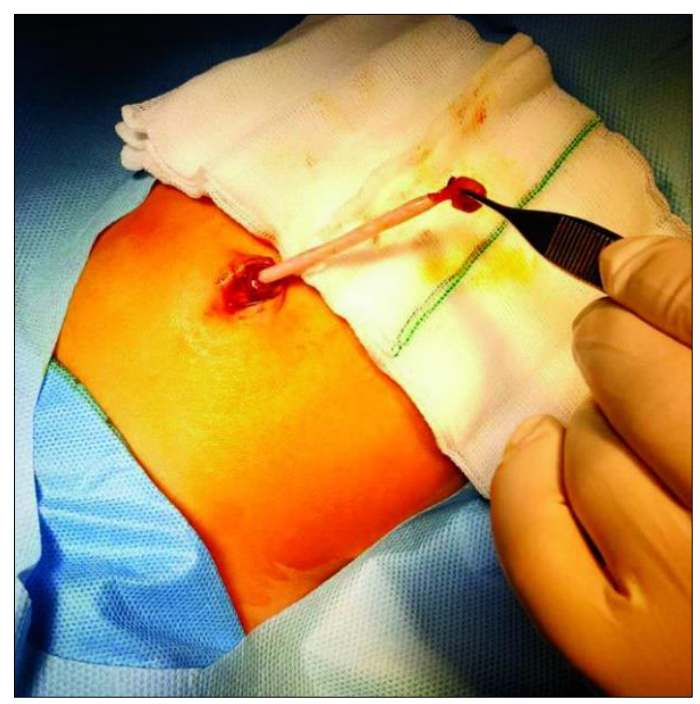

Figure 2: Umbilical appendix found at dissection

\section{DISCUSSION}

Normal development of gut in fetal period involves rapid midgut growth in the sixth week of gestational age followed by its physiological herniation into the coelom. During the tenth and eleventh weeks of gestation, appendicular budding from cecum and re-entrance of jejunum, cecum and appendix into celomic cavity occurs.[6] Rarely due to disruption of this normal bowel transit, various anomalies may develop such as hernia of umbilical cord.[1]

Many usual and unusual contents of hernia of umbilical cord are mid gut, cecum, remnants of omphalomesenteric duct, gallbladder, and rarely liver tissue.[1-3] Vermiform appendix as a content of hernia of umbilical cord is extremely rare. Only few cases of umbilical appendix have been reported on literature search.[4-6] In the index cases although there was no definite history of hernia of umbilical cord in both of our patients but a history of delayed separation of umbilical cords was present.

The tip of vermiform appendix was present at the base of umbilical ring but did not produce noticeable swelling thus remained unnoticed. Only when the umbilical cord separated a reddish umbilical mass appeared and was initially considered as umbilical granuloma. Similarly, Salah et al reported iatrogenic appendicular fistula at umbilicus due to inadvertent ligation of cord containing umbilical appendix.[6]

A reddish tissue at umbilicus has many differential diagnosis ranging from umbilical polyp or granuloma to patent vitellointestinal duct. The diagnosis becomes easier when there is fecal or urinary discharge. In case of little or inconspicuous discharge, the diagnosis may only become overt at surgical exploration.[5,6]

Similarly our patients were managed on the lines of umbilical granuloma and final diagnoses were only reached at the time of surgery. Literature search also elucidated mobile cecum as an incidental finding in approximately half of the reported patients.[5] In our experience, both patients also had mobile cecum without evidence of malrotation. A sustained pull on the cecum due to appendicular herniation may be a reason behind a mobile cecum.

Consent: Authors declared that they have taken informed written consent, for publication of this report along with clinical photographs/material, from the legal guardian of the patient with an understanding that every effort will be made to conceal the identity of the patient however it cannot be guaranteed. 
Authors' Contribution: All authors contributed equally in concept, literature review, and drafting of the manuscript and approved the final version of this manuscript.

\section{REFERENCES}

1. Mirza B, Mirza A, Hashim I, Saleem M. Hernia of umbilical cord: report of three unusual cases. J Neonatal Surg. 2015; 4:16.

2. Hasaniya NW, Premaratne S, Varnes PM, Shin D, Shim W. Hernia into the umbilical cord with incarceration of liver and gall bladder in a newborn. J Pediatr Surg Case Rep. 2013; 1:432-3.
3. Pal K. Congenital hernia of the umbilical cord associated with extracelomic colonic atresia and perforation of gut in a newborn. Afr J Paediatr Surg. 2014; 11:74-6.

4. Fuijkschot J, Wijnen RM, Gerrits GP, Dubois SV, Rieu PN. A neonate with an intact congenital umbilical appendix: an alternative theory on the etiology of the appendico-umbilical fistula. Pediatr Surg Int. 2006; 22:689-93.

5. Choi SO, Eunyoung Jung, and Woo-Hyun Park. Umbilical cord hernia containing vermiform appendix adherent to the sac. J Korean Surg Soc. 2011; 80:161-3.

6. Salah SDG, Almushly RMA, Eltayeb K, Elgaili E. Congenital umbilical appendix. Sudan Med J. 2009; 45.70-4. 